\title{
Congratulations to G.Ya. Dymkin
}

DOI: $10.1134 / \mathrm{S} 1061830909060096$

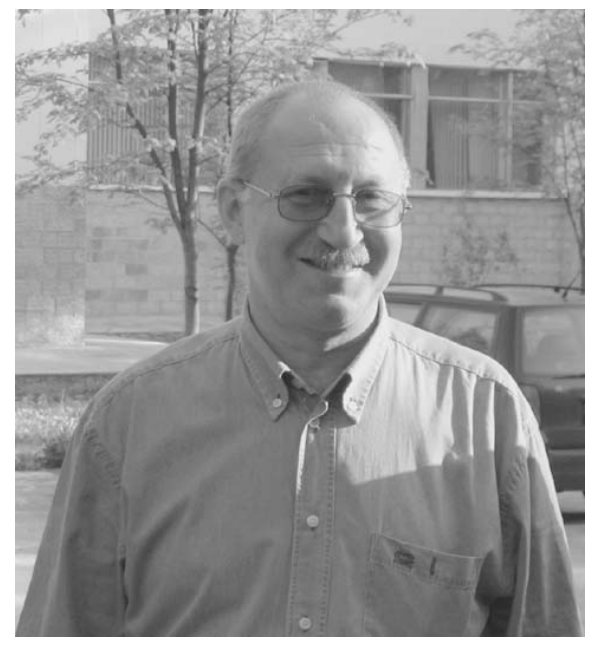

May 1, 2009, marked the 60th birthday of Professor Grigorii Yakovlevich Dymkin, a noted specialist in the field of acoustic testing and diagnostic methods and a member of the editorial board of Defektoskopiya (Nondestructive Testing).

A disciple and successor of Professor Gurvich, one of the developers of classical ultrasonic testing, for many years Dymkin has been successfully developing nondestructive testing techniques in one of the most important fields-railway transport. The activity of Professor Dymkin is highly appreciated in our country: in 2007, he was awarded the Prize of the Government of the Russian Federation in the field of science and technology.

The editorial board and scientific community cordially congratulate Professor Dymkin with his birthday! 